
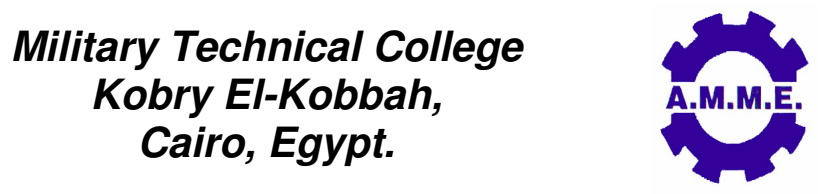
$15^{\text {th }}$ International Conference on Applied Mechanics and Mechanical Engineering.

\title{
ACOUSTIC EMISSION APPLIED TO SLUG VELOCITY DETERMINATION IN TWO PHASE FLOW
}

\author{
M. Alssayh , A. Addali ${ }^{*}$ and D. Mba ${ }^{* \star}$
}

\begin{abstract}
Two phase flow is a common phenomenon in petroleum and chemical engineering. An important feature used to describe two phase flow is the flow regime which varies depending on the individual velocities of the components within the two-phase flow. One of these regimes, the slug regime, can create significant pressure fluctuations that compromise the integrity of the transporting structure (pipes, separators, etc.). This is in addition to other unwanted effects such as flooding at the receiving end, an increase in deposits of hydrates, and corrosion. Under such circumstances the detection of the slug and its associated characteristics are vitally important to the operator.
\end{abstract}

This experimental study investigates the application of Acoustic Emission (AE) technology for detecting slug velocity in two phase (gas/liquid) flow. It is demonstrated that slug velocity can be determined using acoustic emission sensors.

\section{KEY WORDS}

Acoustic Emission, Slug Velocity, Two Phase Flow, Flow Regime.

* Graduate student, School of Engineering, Cranfield University, Cranfield, Beds MK43 OAL, UK. m.a.alssayh@cranfield.ac.uk

** Associate Professor, School of Engineering, Cranfield University, Cranfield, Beds MK43 0AL, UK.

*** Professor, School of Engineering, Cranfield University, Cranfield, Beds MK43 OAL, UK 


\section{INTRODUCTION}

\section{Slug Flow}

In the chemical engineering industry, particularly with gas and liquid transportation pipelines, the slug flow regime is frequently encountered over a wide range of gas and liquid flowrates and over the whole range of pipe inclinations. The slug flow mechanism receives great attention in both engineering and scientific fields because it appears in many industry processes. To gain a better understanding of the characteristics of this flow regime, several theoretical and experimental studies have been conducted to determine and control slug flow parameters. Taitel and Dukler [1] developed a model for the unsteady hydrodynamic behaviour of gas/ liquid slug flow and which predicts slug fluid velocity with of length of slug and other slug parameters. This model is based on the observation of fast moving slug overruns, a slow moving liquid film which is accelerated to full slug velocity. Nydal et al. [2] used a conductance method to determine the mean slug characteristics (hold up, length and velocity) for a large range of gas and liquid velocities in horizontal pipes. Emerson and Leonardo [3] measured the slug velocity of two phase flow in horizontal pipes using the capacitive technique. Gu and Gue [4] conducted experimental investigations of slug development in horizontal two-phase flow using conductivity probes. Fusheg and Feng [5] used a conductivity electrode technique and local cross-correlation to determine slug flow velocity of gas/liquid flow in a horizontal pipe.

However, the techniques that have been used to investigate the slug flow parameters have limitations. The accuracy of conductivity rings and ultrasonic techniques, for example, decreases as the gas void fraction in the pipe increases. Therefore, in order to overcome the limitation of the previous techniques, this paper proposed the implementation of an Acoustic Emission technique to determine the slug transitional velocity in two phase (gas/liquid) flow in horizontal pipes.

\section{Acoustic Emission}

Acoustic Emission ( $\mathrm{AE}$ ) is defined as transient elastic waves within a material or a process producing in the spontaneous release of elastic energy [6]. This elastic wave is of higher frequency than audible sound $(>20 \mathrm{kHz})$ and typically has a frequency range between $100 \mathrm{kHz}$ to $1 \mathrm{MHz}$. AE systems typically consist of: $\mathrm{AE}$ sensors; preamplifiers; cables; and a data acquisition system [4,7].

To understand and interpret an AE signal, knowledge of certain basic phenomena is required. The most widely used features for analysis are, see Figure (1):

- Arrival Time: refers to the time at which the signal amplitude first crosses a predetermined threshold level. This parameter is used to calculate source location.

- Rise time: the time duration between the first threshold crossing of the burst signal and the peak amplitude.

- Amplitude (peak amplitude): the largest voltage within the duration of the signal. This is an essential parameter of the AE signal because the amplitude of the signal must exceed the threshold value for the signal to be detected. 
- Duration: the time interval between first and last threshold crossing in the burst signal. [8, 9].

AE testing has many advantages, including: It can be used for pre-service and inservice testing; It's a global monitoring system which means sensors can detect acoustic signals from large distances; It reduces cost in terms of rapid inspection; Shutdown is not needed and it can detect flaws in earlier stages; It is not sensitive to typical environmental noises; and It can be used simultaneously with other invasive and non-invasive techniques $[8,9]$.

As any other techniques, AE has some limitation and disadvantages such as: It is not repeatable because each loading is different and has a unique stress; the AE waves will be attenuated as they pass through the under test structure; $A E$ is sensitive to other ultrasonic sources such as turbulence and crushing; it requires special sensors and signal processing; and its signals are weak comparing to vibration signals $[8,9]$.

Over the last decade, AE technology has been employed to monitor and investigate the characteristics of multi-phase flow. Yen and Lu [10] distinguished four main regimes (bubbly, slug, churn and annular) in an air/ water two phase flow in a vertical column by using $A E$ and neural network techniques. Albion et al. [11] studied the flow regimes of powder in horizontal pipes by using $A E$ technique. Addali [12] used $A E$ to monitor and measure gas void fraction (GVF), of gas / water two phase flow. Shuib et al. [13] explored the correlation between $A E$ signal and single bubble formation, motion and collapse.

\section{TEST RIG DESIGN}

To investigate the capability of $A E$ to determine slug flow velocity; a two phase flow test rig with all its instrumentation was designed and constructed as shown in Figure (2). A closed loop horizontal pipe with 2" $(50 \mathrm{~mm})$ inner diameter and $22 \mathrm{~m}$ in length was used. $17.4 \mathrm{~m}$ of this pipe was PVC, $4.0 \mathrm{~m}$ was Perspex to allow visual observation of the fully developed flow, and $0.6 \mathrm{~m}$ was of stainless steel to mount the $A E$ sensor on. This pipe was connected to an air compressor with a maximum 10 bar output to feed the test rig with air. A brass gate type valve installed upstream of the gas flow meter used to control the gas flow rate. Tap water was linked to the test rig via a $1 \mathrm{HP}$ pump with a maximum flow rate of $15 \mathrm{~m}^{3} / \mathrm{hr}$. The water flow rate was controlled by using a throttling valve downstream of the pump. Both gas and water were metered before the point at which single phases where combined to form two phase flow using a vortex flow-meter (GF) and an electromagnetic flow-meter (WF) to measure gas and liquid velocities respectively. Temperature and pressure of the air and water were monitored before and after the combination of single phases using pressure $(\mathrm{P})$ and temperature $(\mathrm{T})$ transducers located on the test rig as show in Figure (2). All the digital data of gas and liquid flow rates, temperature and pressure reading, were acquired using the lab view system.

A two channel Physical Acoustics Emission system fitted with a PCl-2 data acquisition card was used for monitoring and acquiring the data of the two phase flow with a sample rate of $2 \mathrm{MHz}$. Two AE Pico sensors with a frequency response of 
150-750 kHz were used. These AE sensors were mounted on the top of the outer face of stainless M12 hexagonal bolts as shown in Figure (3), these bolts were used as waveguides to carry the elastic waves generated from the flow activities to the $A E$ sensors. The output AE signals were pre-amplified at $40 \mathrm{~dB}$. The experiments were carried out at different superficial liquid (VSL) and gas (VSG) velocities controlled using throttling valves downstream of the flow meters.

\section{METHODOLOGY OF THE EXPERIMENTAL WORK}

After conducting many tests to determine the optimum rig design for determination of slug velocity, the two AE Pico sensors were mounted on the two waveguides (M12 hexagonal bolts) placed $20 \mathrm{~cm}$ apart as shown in Figure (3). The waveguides were fitted onto the Perspex pipe section in a specifically designed housing. This housing was constructed to allow for direct contact between the two waveguides and the fluid passing through the pipe. The two AE Pico sensors were mounted on the steel waveguides, which were used as signal carriers from the flow to the AE sensors. After running the experiment at different superficial gas and liquid velocities and analysing the waveforms, it was observed that the signals had short risetimes and distinguishable peaks. This helps to determine the arrival time of each waveform signal and consequently calculate the slug velocity. Figure (4) presents the waveforms of $A E$ signals at 1.1VSL and 1.52VSG using the Pico sensors mounted on flush-mounted rings. The AE system was programmed for a $32 \mathrm{~dB}$ threshold to avoid background noise and a $2 \mathrm{MHz}$ sampling rate.

\section{SLUG VELOCITY CALCULATION AND RESULTS DISCUSSION}

To determine the time delay between two AE waveform signals and hence calculate the slug velocity for gas/liquid flow, tests were undertaken for four different superficial liquid velocities VSL $(0.72,1.02,1.52$ and 2.02) $\mathrm{m} / \mathrm{s}$. At each VSL, four superficial gas velocities VSG $(1.02,1.52,2.02$ and 2.52$) \mathrm{m} / \mathrm{s}$ were used. Thus a total of sixteen tests with various velocities were undertaken. The AE waveforms were analysed to determine arrival times. The arrival time of each $A E$ burst signal was defined by determining the exact time the AE wave exceeded the set threshold and the time delay $(\Delta t)$ of the two simultaneously acquired $A E$ waveforms was calculated by subtracting the arrival time $\left(t_{1}\right)$ of the first burst signal from the arrival time $\left(\mathrm{t}_{2}\right)$ of the second burst signal. The time delay between AE sensors was calculated based on following equation:

$$
\Delta \mathrm{t}=\mathrm{t}_{2-} \mathrm{t}_{1}
$$

where $\Delta t$ is the time delay between the two sensors $(s), t_{1}$ is the waveform arrival time at sensor one (s) and $\mathrm{t}_{2}$ is the waveform arrival time at sensor two (s).

After determining the time delay, slug velocity (Sv) can be calculated using the following equation:

$$
\mathrm{SV}=\mathrm{L} / \Delta \mathrm{t}
$$


where $\mathrm{Sv}$ is the slug velocity $(\mathrm{m} / \mathrm{s})$ and $\mathrm{L}$ is the distance between the two $A E$ sensors $(\mathrm{m})$.

\section{TIME DELAY AND SLUG VELOCITY CALCULATION}

To determine slug velocity, two parameters have to be known. The distance $(\mathrm{L})$ between AE sensors which is $20 \mathrm{~cm}$, and time delay $(\Delta t)$ between $A E$ waveform signals which can be detected by taking different burst signals randomly and defining the arrival time to each waveform burst signal. Randomly selected representative AE waveforms, thirteen in this case, were used to determine time delay and consequently calculate the slug velocity of each run. This number of burst signals was chosen based on a statistical sample size between $10-30 \%$, which can adequately describe the whole population [14]. Table (1) shows an example of time delay and slug velocity calculation at $2.02 \mathrm{VSL}$ and $1.52 \mathrm{VSG}$. From this table the slug velocity is noted to vary between $3.7 \mathrm{~m} / \mathrm{s}$ to $4.1 \mathrm{~m} / \mathrm{s}$ with an average of $3.92 \mathrm{~m} / \mathrm{s}$ and a standard deviation of $0.135 \mathrm{~m} / \mathrm{s}$. This average is $10 \%$ higher than the mixed velocity of the flow, gas and liquid. Figure (5) presents the time delay, slug velocity and an error of each reading at 2.02VSL \& 1.52VSG.

By repeating the same steps for other velocities of VSL and VSG, see table (2), the average of slug velocity differed by between $10 \%$ to $26 \%$ from the mixed flow velocity. The standard deviation of the measured slug flow velocity varied between 0.103 and $0.237 \mathrm{~m} / \mathrm{s}$.

The variation of the slug velocity is due mainly to the variation in the contact area between the slug and the AE sensors which means that apparently similar slugs sometimes do not release the same amounts of energy and this leads to different measured slug arrival times; The slug does not preserve its exact physical shape over the $20 \mathrm{~cm}$ from one sensor to the next, some variation in the shape of the slug occurs and this leads to slightly different signals being picked up by the AE sensors. In addition, the throttling valve and brass gate that control liquid and gas flow respectively are not $100 \%$ accurate; there was a variation in the water throttling valve of $(0.01-0.3) \mathrm{m} / \mathrm{s}$ and in the brass gate valve of $(0.1-0.6) \mathrm{m} / \mathrm{s}$. The variation increased as the flow increased.

\section{CONCLUSIONS}

This work demonstrates the capability of $A E$ technique to determine slug velocity in two phase (gas/liquid) flow. Sixteen different superficial liquid (VSL) and gas (VSG) velocities were investigated and it was concluded that the AE technology has the ability to identify the slug velocity in two phase (gas/water) flow. To improve accuracy the contact response of the AE sensors needs to be investigated, refined and made more precise. 


\section{REFERENCES}

[1] Shuib, H., Addali, A. and Mba, D. (2010), Observation of Acoustic Emission from Bubble Inception and Collapse, WCE 2010, London, UK.

[2] Albion, K., Briens, L., Briens, C. and Berruti, F. (2007), Flow regime determination in horizontal pneumatic transport of fine powders using nonintrusive acoustic probes, Powder Technology, vol. 172, no. 3, pp. 157--166.

[3] Fusheng, Z. and Feng, D. (2010), "A Measurement Method of Slug Flow Velocity of Gas-Liquid Two-Phase Flow in Horizontal Pipe", Instrumentation and Measurement Technology Conference (I2MTC), 2010 IEEE, , no. 3-6 May 2010, pp. $250-254$.

[4] Muravin, D. B. (2009), Acoustic emissions science and technology, available at: www.muravin.com (accessed June/15).

[5] British Standard. (2000), Non-destructive testing - Terminology, Part 9: Terms used in acoustic emission testing, BS EN 1330-9:2000.

[6] Emerson, D. R. and Leonardo, G. J. (2005), A non-intrusive probe for bubble profile and velocity measurement in horizontal slug flows, Flow Measurement and Instrumentation, vol. 16, no. 4, pp. 229-239.

[7] Yen, G. G. and Lu, H. (2002), Acoustic emission data assisted process monitoring, ISA transactions, vol. 41, no. 3, pp. 273-282.

[8] Hellier, C. (2001), Handbook of non-destructive evaluation, McGraw-Hill, New York ; London.

[9] Holroyd, T. J. (2000), The acoustic emission \& ultrasonic monitoring handbook, Coxmoor, Oxford.

[10] Connor,T. (July17, 2011), http://www.drtomoconnor.com/3760/3760lect03.htm (accessed November 25, 2011).

[11] Nydal, O. J., Pintus, S., and Anderussi, P. (1992), Statistical Characterization of Slug Flow in Horizontal Pipes, Int. J. Multiphase Flow, vol. 18, no. 3, pp. 439-453.

[12] Taitel, Y., and Dukler, A. E. (1975), A model for predicting flow regime transitions in horizontal and near horizontal gas-liquid flow, Chemical Engineering Department, University of Houston, Houston, Texas 77004, vol. 22, pp. 47-55-55.

[13] Addali, A. (2010), Monitoring Gas Void Fraction in Two-phase Flow with Acoustic Emission (PhD thesis), Cranfield University, Cranfield University Library.

[14] Gu, H. and Gue, L. (2008), Experimental Investigation of Slug Development on Horizontal Two-phase Flow, Chinese Journal of Chemical Engineering, vol. 16, no. 2, pp. 171-177. 


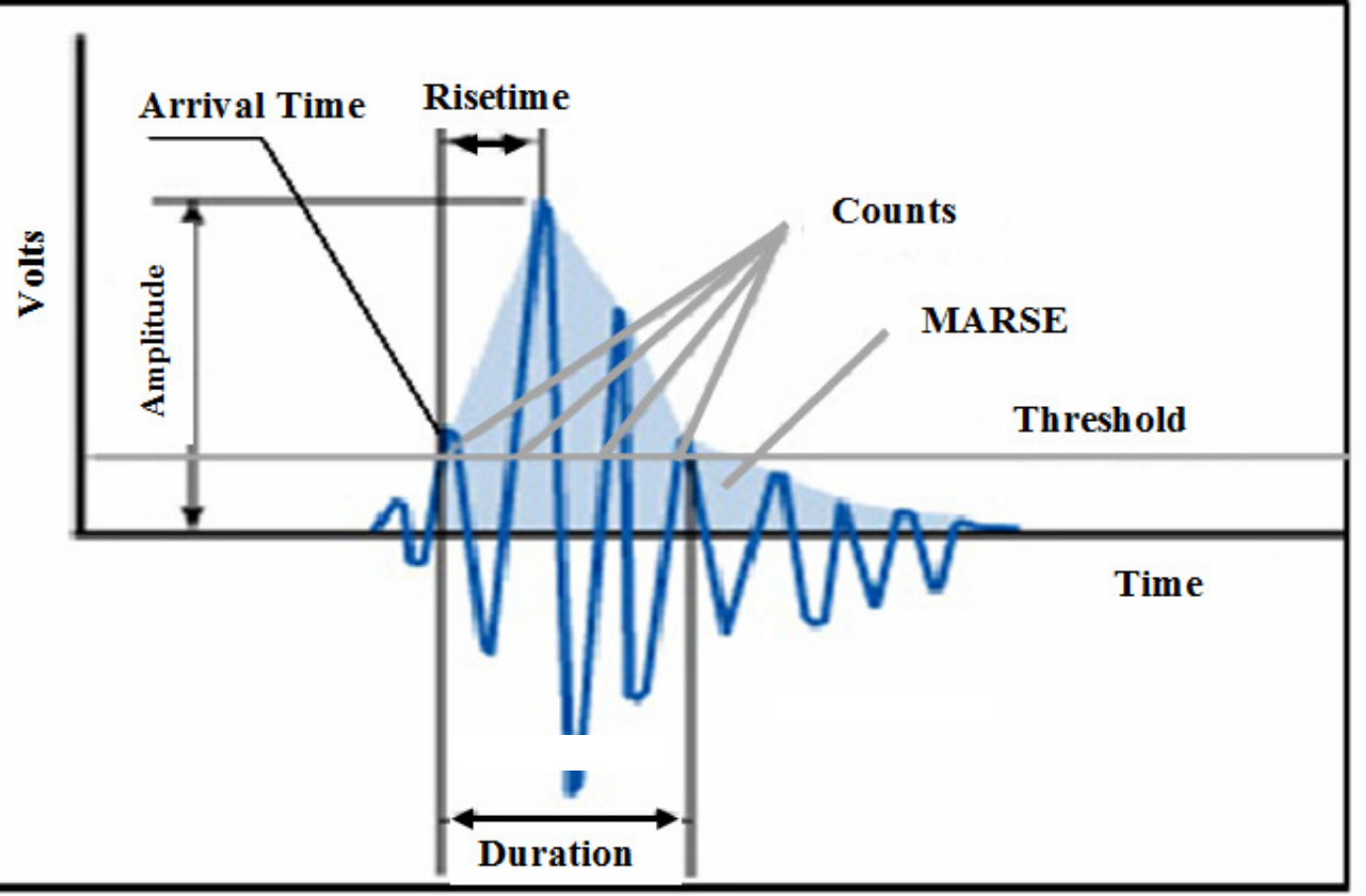

Fig. 1. Typical acoustic emission signals parameters.

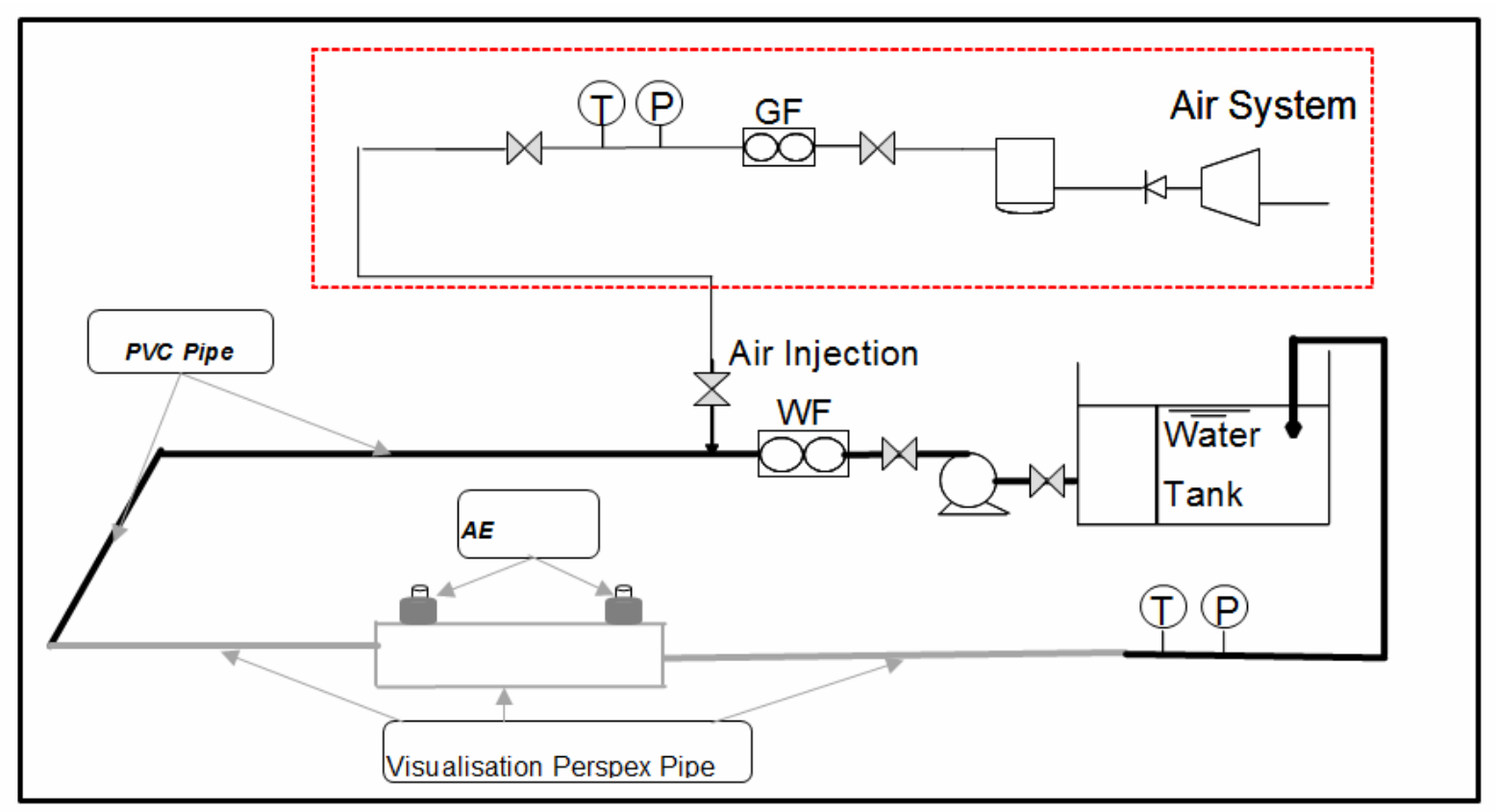

Fig.2. Experimental setup for two-phase slug velocity measurement. 


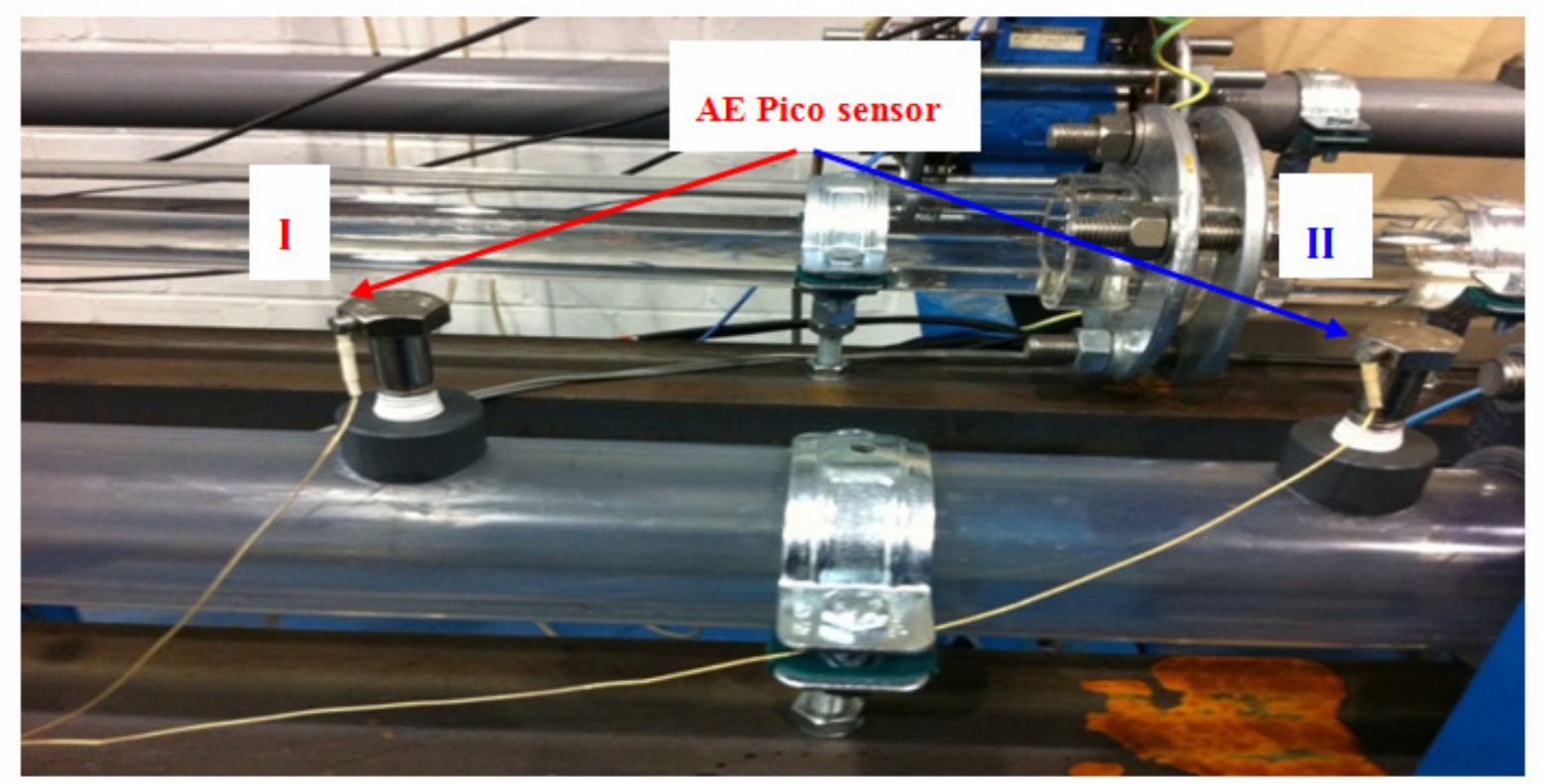

Fig. 3. Waveguides (M12 hexagonal bolts) and AE Pico sensor installation.

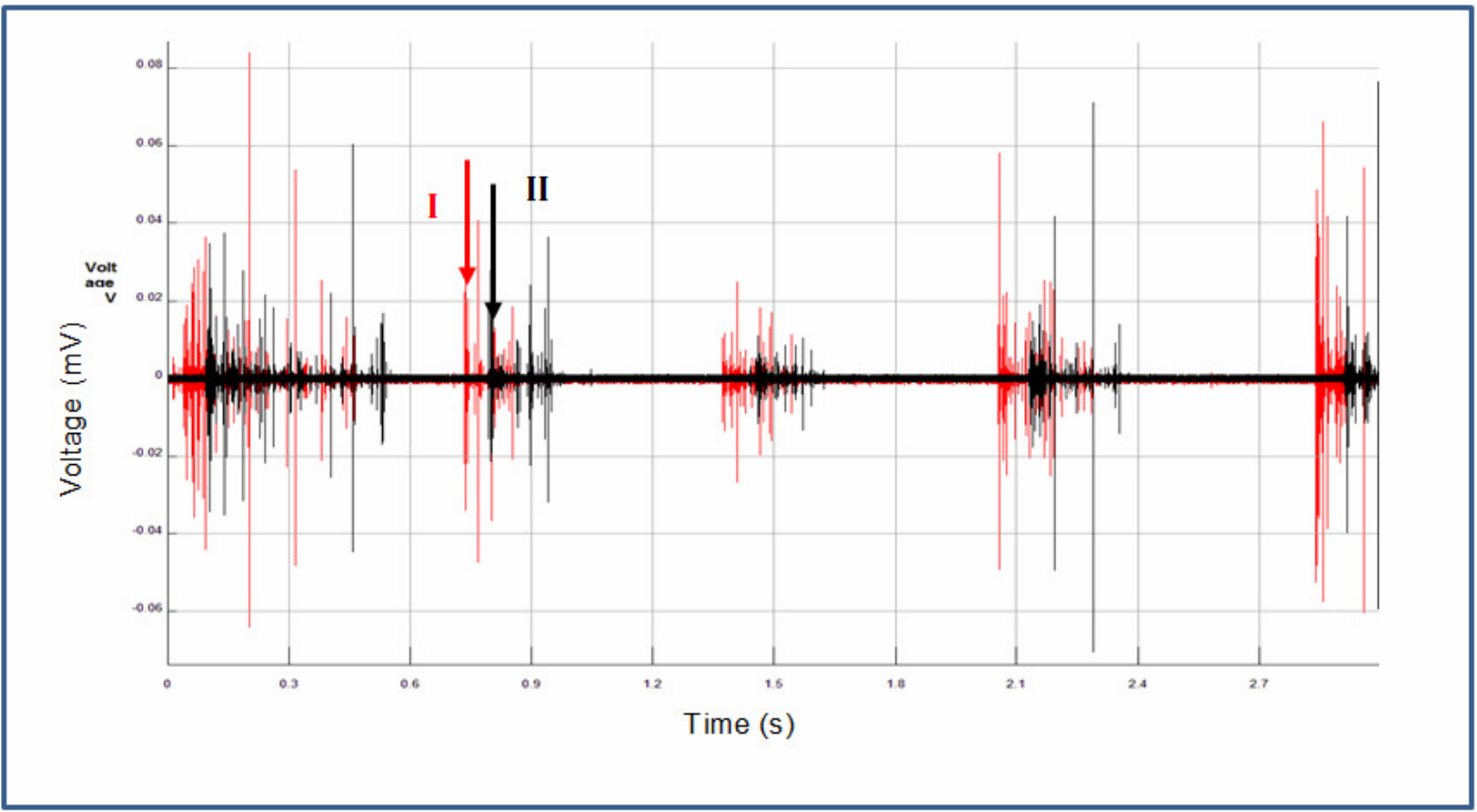

Fig.4. AE waveform at 1.1VSL and 1.52VSG. 


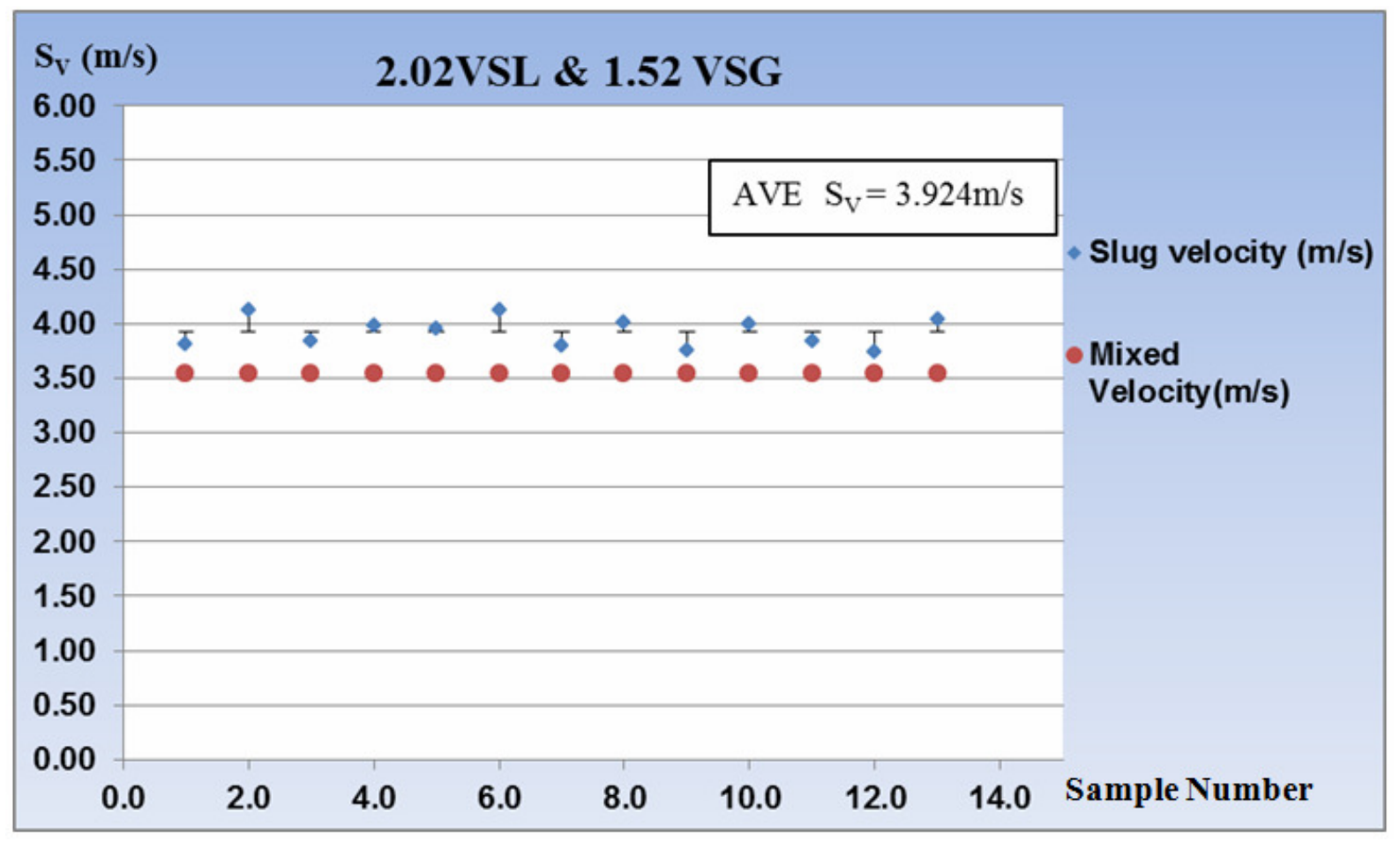

Fig.5. Slug velocity at 2.02VSL and 1.52VSG.

Table 1. Time delays and slug velocities at 2.02 VSL and 1.52 VSG.

\begin{tabular}{|c|c|c|}
\hline \multicolumn{3}{|c|}{$2.02 V_{S L} \& 1.52 V_{S G}$} \\
\hline $\begin{array}{l}\text { Number of } \\
\text { burst signals }\end{array}$ & Time delay (s) & Slug velocity $(\mathrm{m} / \mathrm{s})$ \\
\hline 1 & 0.05251 & 3.809 \\
\hline 2 & 0.04846 & 4.127 \\
\hline 3 & 0.05203 & 3.844 \\
\hline 4 & 0.05017 & 3.986 \\
\hline 5 & 0.05066 & 3.948 \\
\hline 6 & 0.04842 & 4.130 \\
\hline 7 & 0.05273 & 3.793 \\
\hline 8 & 0.04990 & 4.008 \\
\hline 9 & 0.05324 & 3.757 \\
\hline 10 & 0.05001 & 4.000 \\
\hline 11 & 0.05209 & 3.839 \\
\hline 12 & 0.05345 & 3.742 \\
\hline 13 & 0.04958 & 4.034 \\
\hline \multicolumn{2}{|c|}{ Average slug velocity $\left(\mathrm{S}_{\mathrm{V}}\right)$} & 3.924 \\
\hline \multicolumn{2}{|c|}{ Mixed flow velocity $\left(\mathrm{V}_{\mathrm{M}}\right)$} & 3.54 \\
\hline \multicolumn{2}{|c|}{ Standard deviation of Slug velocity } & 0.135 \\
\hline \multicolumn{2}{|c|}{$\%$ difference between $\mathrm{S}_{\mathrm{v}}$ and $\mathrm{V}_{\mathrm{m}}$} & $10.86 \%$ \\
\hline
\end{tabular}


Table 2. Time delays and slug velocities for all flow rates.

\begin{tabular}{|c|c|c|c|c|c|}
\hline $\begin{array}{c}\text { Liquid Flow } \\
\text { Velocity } \\
\left(\mathbf{V}_{\mathbf{S L}}\right) \\
\mathbf{m} / \mathbf{s}\end{array}$ & $\begin{array}{c}\text { Gas Flow } \\
\text { Velocity }\left(\mathbf{V}_{\mathbf{S G}}\right) \\
\mathbf{m} / \mathbf{s}\end{array}$ & $\begin{array}{c}\text { Mixed Flow } \\
\text { Velocity }\left(\mathbf{V}_{\mathbf{M}}\right) \\
\mathbf{m} / \mathbf{s}\end{array}$ & $\begin{array}{c}\text { Average Slug } \\
\text { Velocity (Sv) } \\
\mathbf{m} / \mathbf{s}\end{array}$ & $\begin{array}{c}\text { Difference } \\
\text { (between } \\
\left.\mathbf{S}_{\mathbf{v}} \text { and } \mathbf{V}_{\mathbf{m}}\right) \\
\mathbf{\%}\end{array}$ & $\begin{array}{c}\text { Standard } \\
\text { Deviation } \\
\text { of } \mathbf{S}_{\mathbf{v}} \mathbf{~} / \mathbf{s}\end{array}$ \\
\hline 0.7 & 1.02 & 1.72 & 2.174 & 12.6 & 0.181 \\
\hline 0.7 & 1.52 & 2.22 & 2.733 & 12.3 & 0.203 \\
\hline 0.7 & 2.02 & 2.72 & 3.14 & 11.5 & 0.231 \\
\hline 0.7 & 2.52 & 3.22 & 3.879 & 12.0 & 0.219 \\
\hline 1.02 & 1.02 & 2.04 & 2.47 & 12.1 & 0.103 \\
\hline 1.02 & 1.52 & 2.54 & 3.012 & 11.9 & 0.124 \\
\hline 1.02 & 2.02 & 3.04 & 3.448 & 11.3 & 0.13 \\
\hline 1.02 & 2.52 & 3.54 & 3.892 & 11.0 & 0.195 \\
\hline 1.51 & 1.02 & 2.53 & 2.957 & 11.7 & 0.188 \\
\hline 1.51 & 1.52 & 3.03 & 3.398 & 11.2 & 0.213 \\
\hline 1.51 & 2.02 & 3.53 & 3.874 & 11.0 & 0.111 \\
\hline 1.51 & 2.52 & 4.03 & 4.574 & 11.3 & 0.237 \\
\hline 2.02 & 1.02 & 3.04 & 3.556 & 11.7 & 0.159 \\
\hline 2.02 & 1.52 & 3.54 & 3.924 & 11.1 & 0.135 \\
\hline 2.02 & 2.02 & 4.04 & 4.465 & 11.1 & 0.18 \\
\hline 2.02 & 2.52 & 4.54 & 4.969 & 10.9 & 0.229 \\
\hline
\end{tabular}

